\title{
Dimensões da telenovela em Portugal
}

Clarice Greco Alves

Mestre e doutoranda pela Escola de Comunicações e Artes da Universidade de São PauloECA-USP. Pesquisadora do Centro de Estudos de Telenovela (CETVN) e do Observatório Ibero-Americano de Ficção Televisiva (OBITEL). Bolsista CAPES.

E-mail:claricegreco@usp.br

Resumo: A autora faz uma análise do livro Memórias da telenovela: programas e recepção', lançado em 2011 pela professora Isabel Ferin Cunha, discutindo a importância e a trajetória da telenovela na formação da cultura portuguesa e relacionando-a com a própria história e organização socioeconômica de Portugal.

Palavras-chave: Telenovela, Portugal, história, cultura.
Abstract: The author analyzes the book Memórias da Telenovela: Programas e recepção (Soap Opera Memories: Programs and Reception), launched in 2011 by Professor Isabel Férin Cunha, who discusses the importance and the trajectory of the soap opera (telenovela) in the formation of the Portuguese culture, relating it with Portugal's own history and socio-economic organization.

Keywords: Soap opera (telenovela), Portugal, history, culture.

No livro Memórias da telenovela: programas e recepção², lançado em 2011, a professora Isabel Férin Cunha ${ }^{3}$ percorre a telenovela portuguesa, discorrendo sobre o gênero, sua história e o surgimento de um público fiel. Ferin, que se dedica à pesquisa de telenovela há muitos anos, analisa as transformações da ficção em Portugal e a influência da telenovela brasileira para a consolidação do formato atual português. É assim que o livro se conecta à nossa atualidade e confirma a proximidade geolinguística ${ }^{4}$ e cultural das duas nações, além de trazer um conjunto sistematizado de dados para a construção de uma memória da ficção produzida em Portugal de 1930 a 2005.

O livro é dividido em três partes. A primeira aborda pesquisas sobre os "Contextos históricos e geográficos" da ficção em Portugal, fazendo um levantamento dos fenômenos históricos e políticos que desencadearam o atual modelo de telecomunicações no país. A segunda concentra-se na "Produção e emissão" dos produtos - tanto os brasileiros, com forte presença no país, quanto os de produção portuguesa -, bem como nos resultados de pesquisas realizadas nesse âmbito. A terceira parte, por sua vez, engloba uma série de estudos sobre "Audiências, usos e recepção", focando pesquisas voltadas ao público telespectador.

1. CUNHA, Isabel. Memórias da telenovela: programas e recepção. Lisboa: Livros Horizonte, 2011.

2. Ibid.

3. Isabel Ferin é professora da Universidade de Coimbra, licenciada em história pela Faculdade de Leras de Lisboa. Fez mestrado e doutorado em Ciências da Comunicação na Universidade de São Paulo e pós-doutorado na França (CNRS). Pesquisa televisão e ficção televisiva e coordena a seção portuguesa do Observatório Ibero-americano de ficção televisiva (OBITEL).

4. Conceito utilizado por Sinclair (1999) para explicar uma cultura definida não pela geografia, mas por fronteiras e metáforas da nação que compartilham o mesmo idioma, o que seria a base para a distribuição dos programas de televisão. SINCLAIR, John. Latin American television: a global view [Televisão latino-americana: uma visão global]. New York: Oxford University Press, 1999. 
comunicação \& educação • Ano XVII • número 2 • jul/dez 2012

No percurso traçado por Ferin sobre os contextos históricos e geográficos, a autora inicia apontando parâmetros cronológicos que se fundamentam em marcos históricos, políticos e sociais dos media. Assim analisa, no primeiro capítulo, as transformações dos meios de comunicação a partir do Estado Novo, fase que engloba as décadas de 1930 a 1974. Essa primeira abordagem histórica é importante para a compreensão do contexto português e da entrada da ficção e sua consolidação na grade televisiva e nos hábitos da sociedade.

Férin divide o Estado Novo português em cinco períodos. O primeiro se dá quando surge o rádio, ainda sustentado pelo governo ditatorial, que controlava seu conteúdo. Nesse período, a TV se tornou porta-voz da política oficial do Estado Novo e o governo passou a investir neste veículo - assinalando uma fase de grande crescimento do público televisivo, que se diversifica devido à escolaridade obrigatória, à migração e ao surgimento de novas classes médias urbanas.

O segundo período de mudanças históricas se dá a partir da Revolução de 25 de abril de 1974, quando é extinta a censura. Segundo a autora, "durante todo esse período o país esteve em revolução cultural". Segue-se a ele um terceiro período, de normalização democrática e modernização do país e dos meios de comunicação. Essa fase é destacada pela autora por meio da primeira telenovela brasileira exibida em Portugal - "Gabriela", em 1977. O fato dá início a um ciclo que só se alterará com o fim do monopólio estatal e abertura de emissoras privadas em 1992. Expande-se então o consumo de produtos culturais - especialmente brasileiros, por meio da música, cinema e literatura - e aumenta o número de espectadores, cobertura e horas de TV transmitidas. Segundo Ferin, as ficções brasileiras foram responsáveis, nessa fase, por criar a receita de sucesso do prime-time português, que é idêntico ao nosso:

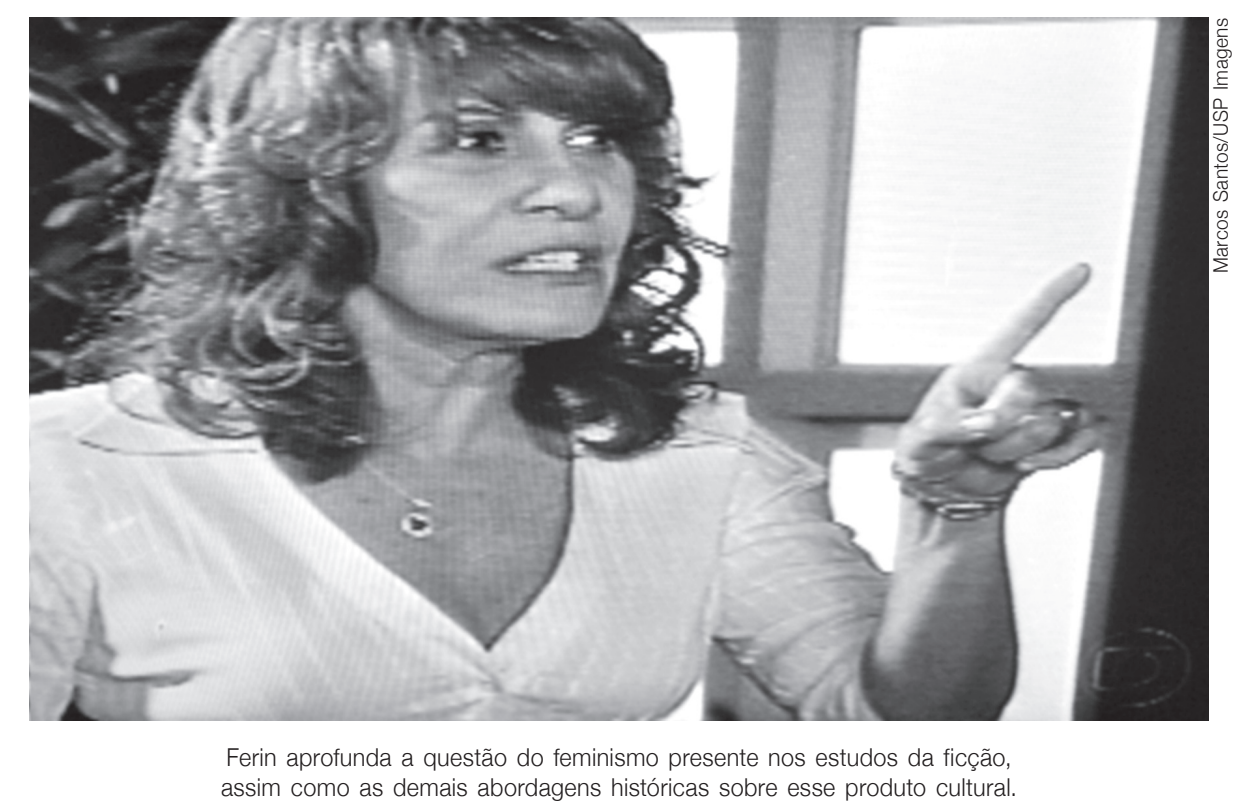


a grade de horários formada por telenovela brasileira - telejornal - telenovela brasileira. De acordo com dados apresentados pela autora, entre 1980 e 1989 foram exibidas 37 telenovelas brasileiras em Portugal.

O quarto período é marcado pelo início das atividades dos operadores privados, como TVI e SIC, criando concorrência com os canais públicos RTP1 e RTP2, e pelo papel desempenhado pela ficção nessa transformação. Esta fase foi também de grande aumento do número de empresas, operadoras, público e programas. Dados da autora mostram que, de 1990 a 1999, foram levadas ao ar 48 ficções brasileiras nos canais RTP1 e RTP2, 67 na SIC e sete na TVI totalizando 122 títulos brasileiros exibidos na década. A emissora SIC assinou um contrato de exclusividade para veiculação das ficções brasileiras, abrindo um novo mercado de produção e atuação nos outros canais e desencadeando a vinda de profissionais brasileiros qualificados e experientes (a maioria oriundos da TV Globo) para apoiar as novas produtoras portuguesas.

Por fim, o quinto período destacado por Ferin é uma fase de diversificação da programação, provocada pela concorrência entre os canais privados, dentro dos quais cresce a produção e transmissão de ficção. Entre 2003 e 2004 a ficção foi o gênero que contabilizou mais horas de exibição - e a TVI começa, a partir daí, a ultrapassar a audiência da SIC com ficção portuguesa.

A descrição do processo histórico apresentado no primeiro capítulo do livro, envolvendo os meios de comunicação e a ficção portuguesa, é realizada de maneira clara e detalhada, sendo importante para a compreensão dos fenômenos culturais em Portugal e de grande relevância para os estudiosos que se proponham a aprofundar análises sobre produtos culturais no país.

No segundo capítulo, intitulado "Das soap operas às telenovelas: memória de produção e pesquisa”, Ferin faz uma revisão da literatura sobre o que chama de gênero soap operas ${ }^{5}$ e da continuidade entre as radionovelas e sua migração para a televisão. A autora define soap opera como um gênero criado para integrar vários elementos da tradição literária ocidental, como o apelo emocional, e os problemas conjugais e de família, entre outros temas típicos do melodrama - e mostrando, com muita frequência, a figura de mulheres independentes. Outras características são a narrativa seriada, a concepção de neverending story e sua exibição como obra aberta.

O capítulo discute diversos estudos sobre a ficção a partir do questionamento de acadêmicos e jornalistas a respeito do impacto desses programas na sociedade. Partindo do pensamento de Charlotte Brunsdon ${ }^{6}$, que afirma que os estudos surgem com o pensamento feminino e a entrada de mulheres na academia, Ferin aprofunda a questão do feminismo presente nos estudos da ficção, assim como as demais abordagens históricas sobre esse produto cultural - citando, inclusive, o acervo do Centro de Estudos de Telenovela da USP (CETVN-USP) e a Revista Comunicação \& Educação por sua bibliografia em telenovela.

No mesmo capítulo, Ferin aborda a telenovela brasileira por uma perspectiva histórica, ressaltando os diversos períodos de sua evolução, características
5. Isabel Ferin chama de gênero o que alguns autores, como os do Centro de Estudos de Telenovela da USP, chamam de formato. O gênero diz respeito ao conteúdo, que no caso da soap opera é melodramático. O formato refere-se à produção, por exemplo, em capítulos ou episódios de longa ou curta serialidade. Essa é a principal diferença entre os formatos soap opera (de narrativa extremamente longa) e telenovela. A única soap opera brasileira é "Malhação".

6. BRUNSDON, Charlotte. The feminist, the housewife and the soap opera [A feminista, a dona de casa e a telenovela]. Oxford: University Press, 2000. 
comunicação \& educação • Ano XVII • número 2 • jul/dez 2012

particulares e internacionalização do formato. Um tópico específico, "identidade das telenovelas brasileiras", analisa as principais mudanças de paradigma da produção no Brasil, apresentando uma breve história da Rede Globo de Televisão e a importância da internacionalização de seus conteúdos. Demonstra, assim, o papel crucial da telenovela brasileira na história das ficções portuguesas.

O terceiro capítulo, "Sobre a cultura de massa e o consumo televisivo: um balanço acadêmico", faz um levantamento de inúmeras pesquisas e teses desenvolvidas na Europa, nos Estados Unidos e na América Latina - perpassando os principais estudos sobre o preconceito em relação à cultura de massas, que seria oposta à erudita à qual a elite prefere dar atenção. $\mathrm{O}$ capítulo avança, ainda, pelos pensadores da Indústria Cultural e pela visão pessimista da teoria Crítica na Escola de Frankfurt, até os estudos franceses e ingleses que alteram essa premissa. Aborda ainda estudos sobre os gêneros e formatos televisivos, bem como sobre o modos ficcional e lúdico em Portugal, destacando três principais orientações: os estudos de caso, que visam entender as especificidades portuguesas, as análises teórico-críticas comparativas e ilustrativas das teorias expostas e as perspectivas de consumo e estilos de vida, que buscam compreender as especificidades portuguesas com contribuições de outras áreas de estudo. Por fim, discorre sobre os estudos a respeito da produção e consumo de gêneros lúdicos e ficcionais, mostrando que os programas de ficção estão no topo da grade televisiva em horas de produção de 1999 a 2006. A pesquisadora discorre sobre os títulos de maior impacto na época, entre os quais uma coprodução com a Rede Bandeirantes, "Paixões proibidas" (2007), e as telenovelas brasileiras "Páginas da vida", pelo impacto causado pela discussão sobre Síndrome de Down, e "Paraíso tropical". Por fim, menciona como importantes investigações sobre a ficção televisiva os projetos Eurofiction e OBITEL, este último desenvolvido em 11 países ibero-americanos e coordenado pelo Centro de Estudos de Telenovela da ECA-USP.

A segunda parte do livro enfoca a "Produção e emissão" dos produtos ficcionais. Ferin inicia com um capítulo sobre a revolução provocada na televisão portuguesa pela telenovela brasileira "Gabriela", transmitida em 1977, comentando ainda acontecimentos marcantes do mesmo ano, que derivam de um período de transição em Portugal até a entrada do país na União Europeia, em 1985. Nessa época a imprensa voltava-se para assuntos e produtos vindos especialmente de Angola, Brasil, Moçambique e Timor, devido à migração crescente e por serem países de língua portuguesa.

A autora apresenta, então, uma pesquisa desenvolvida sobre os meios de comunicação impressos de maior tiragem na época e sobre a existência de secções que abordavam a televisão - analisando o ano de 1977, sob a perspectiva da transição portuguesa e do impacto da telenovela "Gabriela" na televisão local. Além das telenovelas, o Brasil estava presente em teatros, livrarias, músicas e cinema. O capítulo segue com destaque para as notícias de "Gabriela" que associavam a telenovela com a agenda política, transformando-a em história dos anos revolucionários e de 1977. Segundo pesquisa da autora, a imagem 




O estudo demonstra o papel crucial da telenovela brasileira na história das ficções portuguesas.

da mulher nos papéis femininos era o principal foco dos artigos, o que teria influenciado a emancipação das mulheres. Assim, a telenovela é inserida na agenda setting do país, criando uma relação cultural intensa entre o produto brasileiro e a nação portuguesa. De acordo com Ferin, “o produto 'Gabriela', apresentando outros falares da língua e outras vivências da cultura em português, revela a existência de um espaço lusófono a potenciar" 7 .

Outro fato interessante apontado sobre "Gabriela" é que a telenovela, formato anteriormente voltado às mulheres, captou um grande público masculino. Nessa época fala-se pela primeira vez na prática de assistir à telenovela nos cafés e associações, criando um sentimento de união pelo fato da "fruição conjunta de exibição" . Além disso, Ferin afirma que a telenovela "Gabriela" alfabetizou o país em um novo gênero e estética, inaugurando em Portugal o que chamaram de país televisivo, devido à massificação das audiências centrada na televisão.

Outra discussão presente no quinto capítulo do livro, intitulado "As 'agendas' da telenovela brasileira em Portugal revisitadas", passa pela transnacionalização de conteúdos e pela globalização, temas pertinentes a esse século marcado por múltiplas telas, nas quais o conteúdo viaja e transita quase livremente. Featherstone $^{9}$ afirma que uma comunidade nacional é criada a partir de um repositório comum de mitos, heróis, acontecimentos, paisagens e recordações, e que estes elementos são constantemente negociados num contexto de globalização. As telenovelas e demais produtos da Indústria Cultural incluem-se nesse grupo e se baseiam, ainda, na língua e nos fluxos de mídia.

Outra pesquisa de grande relevância e interesse para o Brasil é apresentada no sexto capítulo, "Da telenovela à prostituição", que questiona se há relação entre a imagem da mulher na telenovela brasileira, a imigração brasileira e os contornos sociais que envolvem sua aceitação e integração em Portugal. Estima-se que cerca de 120 mil cidadãos brasileiros estejam vivendo em Portugal, dos
7. FERIN, Isabel. Memórias da telenovela: programas e recepção. Lisboa: Livros Horizonte, 2011, p. 100.

8. Ibid., p. 97.

9. FEATHERSTONE, M. O desmanche da cultura: globalização, pós-modernismo e identidade. São Paulo: SESC, 1977. 
comunicação \& educação • Ano XVII • número 2 • jul/dez 2012

10. Argentina, Brasil, Chile, Colômbia, Espanha, Estados Unidos, Equador, México, Portugal, Uruguai e Venezuela.

11. Em caso de interesse mais detalhado da análise apresentada neste capítulo, conferir os Anuários Obitel 2006, 2007, 2008, 2009, 2010 e 2011, que apresentam os capítulos de cada país e um comparativo geral da ficção ibero-americana.

12. HALL, Stuart. A identidade cultural na pós-modernidade. Rio de Janeiro: DP\&A, 2003.

13. BRUNSDON, Charlotte; MORLEY, David. Everyday Television: $\mathrm{Na}$ tionwide. London: British Film Institute, 1978.

14. ANG, len. Watching Dallas: Soap opera and the melodramatic imagination. London: Methuen, 1985.

15. MARTIN-BARBERO Dos meios às mediações: comunicação, cultura e hegemonia. Rio de Janeiro: Editora UFRJ, 2008.

16. Silverstone, Roger. Television and Everyday Life [Televisão e a vida cotidiana]. London and New York: Routledge, 1994.

17. LOPES, Maria Immacolata Vassallo de BORELLI, Silvia Helena Simões; RESENDE, Vera da Rocha. Vivendo com a telenovela: mediações recepção, teleficcionalidade. São Paulo: Summus Editorial, 2002. quais $40 \%$ são mulheres. Inicialmente, a autora descreve a realidade socioeconômica de diversas regiões de Portugal e a imagem da família e da mulher.

De acordo com vários estudiosos da recepção desses produtos culturais, é possível pensar na imagem da mulher por meio das soap operas e de seu impacto no público telespectador. De acordo com esse princípio, as imagens teriam criado nos portugueses um imaginário estereotipado da mulher brasileira como arquétipo de sensualidade, disponibilidade sexual e transitoriedade afetiva. Segundo Ferin, a telenovela brasileira apresenta três modelos de mulher: a mulher perfeita, a mulher moderna e a mulher independente. A pesquisadora expõe, então, uma análise de doze telenovelas brasileiras exibidas da década de 1970 aos anos 2000, que fizeram sucesso e trataram de temas relativos às mulheres, para que esses três modelos de personagens femininos fossem observados.

Finalizando a segunda parte está o sétimo capítulo, "Ficção televisiva seriada: 2007-2009", que apresenta uma análise da produção ficcional de Portugal nos anos de 2007 a 2009, na perspectiva dos estudos desenvolvidos no Observatório Ibero-americano de Ficção Televisiva (OBITEL), coordenado pelo Centro de Estudos de Telenovela da ECA-USP (CETVN), pela prof ${ }^{a}$. Maria Immacolata Vassallo de Lopes (coordenadora do CETVN) e por Guillermo Orozco Gómez, do México.

O projeto OBITEL apresenta os principais assuntos que concernem aos meios de comunicação e analisa as ficções produzidas e exibidas em 11 países $^{10}$, trazendo um panorama completo da ficção na grade televisiva de cada país. A análise de Portugal, apresentada aqui, compara a produção nacional com a importada na grade televisiva, por meio de análises do share e da audiência por canais, das ficções de sucesso e tendências de audiência e programação, dos programas de TV mais destacados e de maior audiência por ano, e de uma análise quantitativa do número de títulos e horas de produção, classificados por faixa horária e formatos. A observação culmina na discussão sobre as tendências na serialidade e audiência, chegando ao debate sobre a ficção em múltiplas plataformas e a transmidiação dos produtos ${ }^{11}$.

A terceira parte do livro, "Audiências, usos e recepção", faz, no capítulo oito, um apanhado teórico dos estudos da recepção na Europa, Estados Unidos e América Latina. Cita a importância do trabalho de autores como: Stuart Hall ${ }^{12}$ e a identidade; os estudos de recepção de David Morley e Charlotte Brunsdon ${ }^{13}$, com a análise da série nationwide, e de Ien Ang ${ }^{14}$, sobre o seriado "Dallas"; o trajeto Dos meios às mediações, traçado por Martín-Barbero ${ }^{15}$; e os estudos de Silverstone em Television and everyday life $e^{16}$ - além da completa análise de recepção da telenovela brasileira realizada pela USP no livro Vivendo com a telenovela, de Lopes, Borelli e Resende ${ }^{17}$.

O capítulo discute, ainda, a evolução do share nas telenovelas noturnas e séries, passando da audiência a uma análise da ficção seriada e salientando a influência latino-americana nesta área, presente desde o início da década de noventa - citando, em especial, as pesquisas brasileiras e estudos de recepção do Centro de Pesquisa de Telenovela da Universidade de São Paulo (CETVN-ECA/ 
USP). Ferin aponta, também, alguns autores latino-americanos e europeus que se destacam no cenário das pesquisas acadêmicas sobre a ficção televisiva. A autora reconhece, nesses estudos, apontamentos para quatro linhas de pesquisa: o impacto das telenovelas nos comportamentos privados e públicos; a atualização de mitos e estereótipos sobre o Brasil; o interesse masculino pelas telenovelas, especialmente as brasileiras; e as condicionantes etárias, de nacionalidade e pertença étnica que parecem marcar a adesão aos conteúdos ficcionais das telenovelas portuguesas ou brasileiras.

Para fechar o agrupamento de análises de diversos aspectos da telenovela em Portugal, Ferin oferece, no nono capítulo, os resultados de seu estudo sobre os imigrantes, desenvolvido no âmbito do Estudo de Recepção dos Meios de Comunicação Social Portugueses. O estudo, que se dá em torno dos conceitos de identidade, diáspora, diferença, mediascape e cidadania, foi realizado por meio de grupos focais com 61 imigrantes, entre ucranianos, romenos, brasileiros e provenientes de países africanos de língua oficial portuguesa. O estudo constatou que, em todos os grupos, figuravam entre os programas preferidos aqueles de informação, futebol e telenovelas.

Quanto às especificidades, a pesquisa revela dados interessantes, como o grupo de imigrantes oriundos de países da África de língua oficial portuguesa que dava preferência ao canal RTP África, mesmo com críticas a ele. Também em relação aos brasileiros, o estudo mostra que os imigrantes apresentam grande interesse nas telenovelas, enquanto demonstram insatisfação com os noticiários portugueses no que diz respeito a uma apontada degradação da imagem do brasileiro em Portugal. Outro resultado interessante apresentado por Ferin diz respeito aos imigrantes do leste europeu, que manifestaram insatisfação em relação à qualidade e pouca quantidade de informação sobre seus países. Neste grupo foi assinalado também o consumo de telenovelas, mesmo com problemas de compreensão da língua.

Este estudo encerra a caminhada cultural exposta pelo livro de Isabel Ferin, Memórias da telenovela: programas e recepção, por meio de diversas pesquisas desenvolvidas sobre a ficção brasileira e portuguesa. A contribuição da obra para o campo é confirmada pelas abordagens tanto dos aspectos teóricos e referências ao estado da arte no campo acadêmico quanto pelas análises empíricas desenvolvidas com rigor metodológico, de grande auxílio a pesquisadores e estudantes da área. Ressalta, ainda, o impacto das telenovelas brasileiras na sociedade, no mercado televisivo português e na construção da imagem dos brasileiros em Portugal, além de confirmar a proximidade entre a cultura e os hábitos brasileiros e portugueses, o que caracteriza esses países como nações irmãs. 


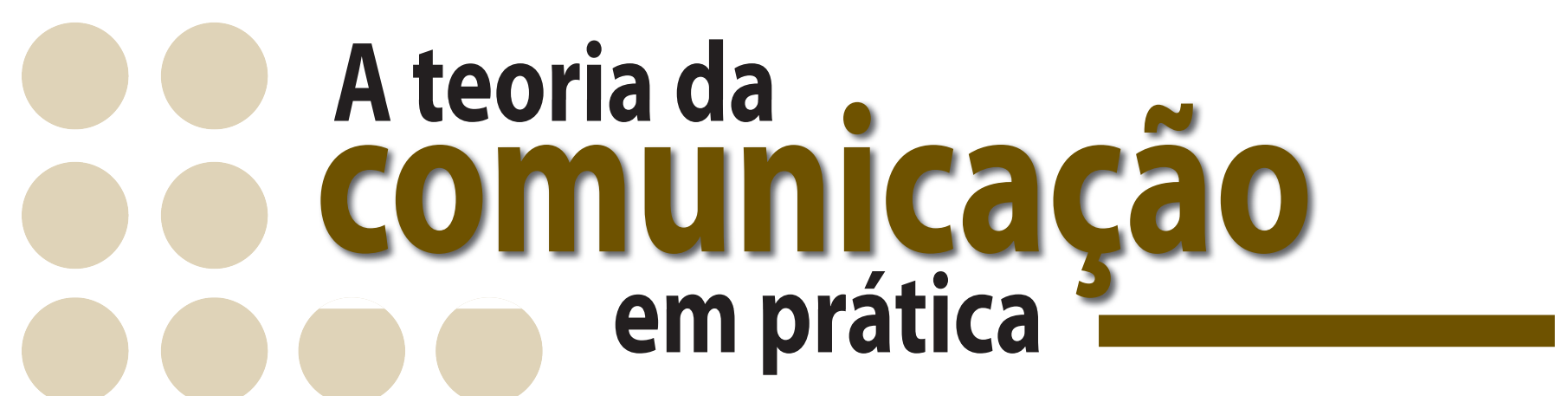

Por um comunicador afinado com as técnicas, mas, principalmente, atento ao importante papel dos meios de comunicação na construção de um mundo ético e justo, possível apenas se os valores cristãos forem os elementos norteadores de seu trabalho.

Para o profissional ou amador, para o leigo ou religioso, gente que quer exercer a comunicação de forma atuante e comprometida, estas obras trazem conceitos, dicas, orientações e exemplos práticos para a produção nas diferentes áreas, aplicáveis tanto em ambientes profissionais quanto em escolas, associações, centros comunitários, paróquias etc.
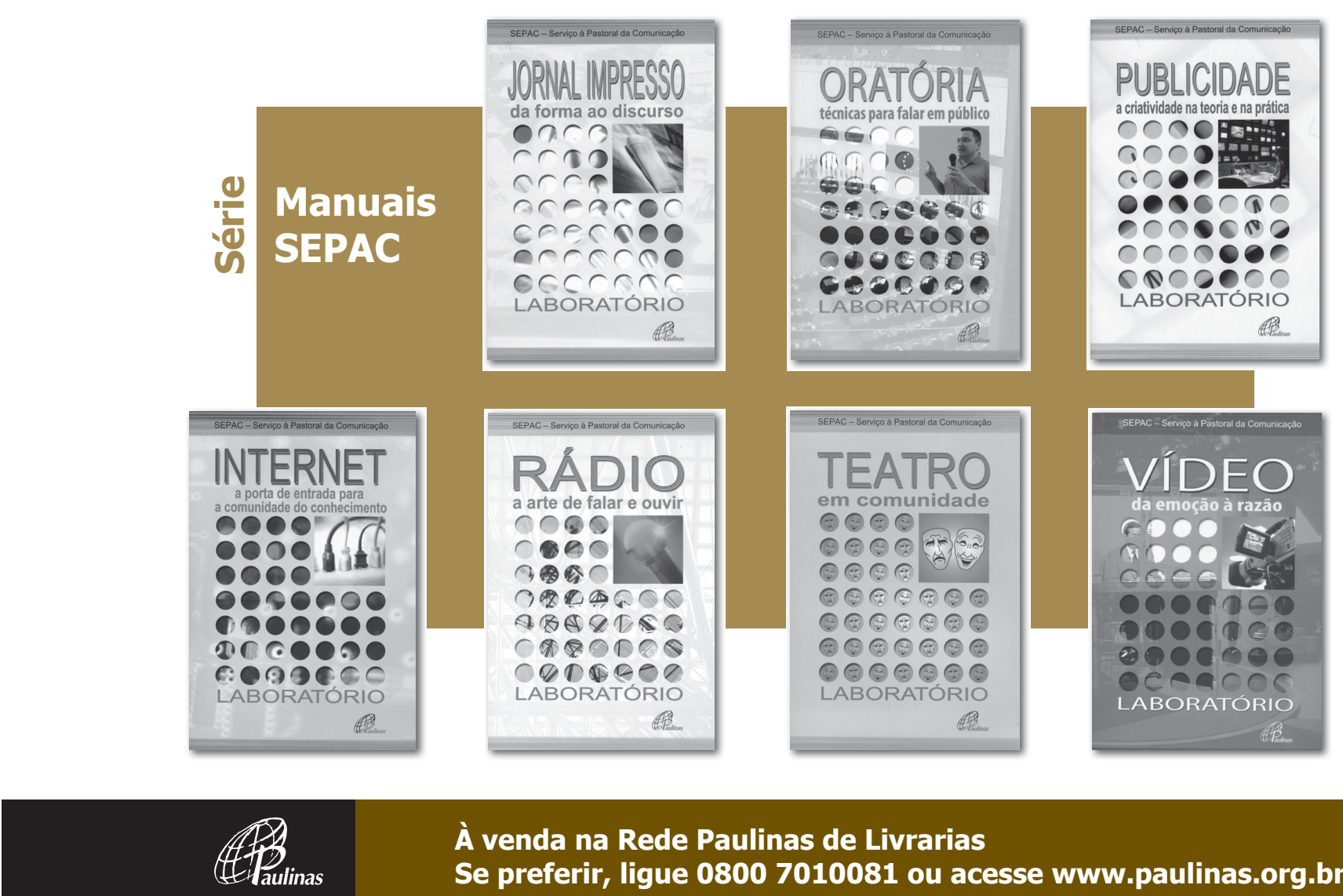

À venda na Rede Paulinas de Livrarias Se preferir, ligue 08007010081 ou acesse www.paulinas.org.br 